\title{
Faculty Learning Processes: A Model for Moving from Scholarly Teaching to the Scholarship of Teaching and Learning
}

\begin{abstract}
This essay explores the development and conceptual validation of the Faculty Processing Model for SoTL through anecdotal reports gathered from six institutions and additional survey data collected from three institutions. The results identified how faculty learning occurred through faculty development activities across various campuses and how that faculty learning cumulatively represented distinctive developmental stages that led to both cognitive and affective transformations for the professors' and their students' learning. This analysis provided a first step in understanding the efficacy of faculty development activities in relation to their impact on student and faculty learning and upon practicing the Scholarship of Teaching and Learning.
\end{abstract}

\section{KEYWORDS}

faculty learning; faculty development; scholarly teaching; student learning.

Although many colleges and universities embrace and reward participation in the Scholarship of Teaching and Learning (SoTL), there is still uncertainty about the impact of faculty development programs designed to move faculty from learning about their own teaching practices to engaging in SoTL in order to enhance student learning in the classroom (Hubball \& Burt, 2006; Hoessler, Britnell, \& Stockley, 2010; Ocha, 2011; Wang \& Hurley, 2012). Professors with years of teaching experience often make commitments to certain pedagogies without ever questioning their own evolving and unfolding understanding of a particular phenomenon and their students' ability or inability to grapple with a content area the professor has already mastered (Feezel \& Welch, 2000). Yet, surprisingly little is understood about what theoretical frameworks are most effective in explaining the way faculty members learn about or incorporate their knowledge of scholarly teaching into their cognitive schema. Without this understanding, even a concentrated institutional commitment to enhancing SoTL will vary in its ability to increase students' capacity for learning in a particular class (Hubball \& Burt, 2006).

Like Lawler (2003), we suspected that "incorporating adult learning principles into our professional development activities and viewing teachers as adult learners may be a 
paradigm shift" (p. 19), especially in determining the efficacy of how a professor's learning impacts student learning. In this essay, we explicate how the Faculty Processing Model for SoTL was first developed from anecdotal reports gathered from six institutions ${ }^{1}$ that identified how faculty learning occurred through faculty development activities across the various campuses and how faculty learning cumulatively represented distinctive developmental stages that led to both cognitive and affective transformations for the professors' and their students' learning. We began by exploring the model's stages to illustrate the places where faculty members consolidate learning and use their pedagogical and curricular knowledge (Kreber \& Cranton, 2000) to engage in activities that influence the next phase of a faculty member's development.

\section{CONCEPTUALIZING THE FACULTY PROCESSING MODEL FOR SOTL}

We began our inquiry of the SoTL faculty development process by collecting anecdotal information from each member of the Carnegie Cluster team through the sharing and recording of her or his own SoTL learning journey. Next, we asked colleagues at a joint SoTL workshop to describe themselves as a learner (Gayle, Randall, \& Langley, 2007). What emerged from these discussions led us to consult Weston and Alpine's (2001) work, the University of Portland's Statement on Scholarly Learning (2003), Bransford, Brown, and Cocking's (2000) model of learning, and Shulman's (2002) Table of Learning. The resulting Faculty Processing Model for SoTL that emerged from our cooperative investigations describes a process that is more circular than linear, because faculty movement occurred through stages and bridging phases differently, depending upon the issue being studied or implemented and the professor's level of exposure to the ideas presented.

Our preliminary data indicated that the professor's aptitude for constructing her or his own knowledge about student learning and incorporating that knowledge into her or his teaching was influenced by the faculty member's ability to move beyond disciplinespecific teaching strategies and tactics. Additionally, the faculty members' confidence in their capabilities to explore and implement new ideas appeared to be related to their ability to bring theoretical and pedagogical knowledge to specific teaching and learning situations. Faculty descriptions of their learning styles simultaneously indicated characteristics of more than one of the emerging yet identifiable stages and bridging phases in moving toward practicing SoTL.

The conversations among faculty participating in our model development illustrated a struggle with their own readiness to engage in the work required to move to a higher level of understanding about teaching and learning. These professors shared how faculty attitudes about, and the willingness to embrace, new teaching tactics and strategies impacted the entire university community as well as the professor's own cognitive and affective processing. The participating faculty members reported that faculty development activities that focus on critical discussions about teaching and learning must encourage the self-confidence to embrace critical ideas about one's own teaching as well as ways to enhance one's creative capabilities in enacting new ideas.

The cognitive processing encouraged by the reported faculty development learning activities appeared similar to the student learning process that Shulman (2002) described. Professors as faculty development students appeared to move from surface-level engagement to a deeper understanding of the teaching and learning process only by willingly engaging in the experience, responding to that experience, and internalizing the lessons 
learned from the experience (Shulman, 2002). As Bransford, Brown and Cocking (2000) articulated in How People Learn, there appeared to be a circular process that allowed faculty learners to relate what they were experiencing and experimenting with to what they already knew before moving to a new level of understanding that incorporated any refinement to their existing ways of thinking. Faculty members, like the students in Bransford, Brown, and Cocking's (2000) book, reported that they struggled to incorporate new knowledge into their existing cognitive schema.

The Faculty Processing Model for SoTL emerged as circular in nature with overlapping periods of reflection that allowed individuals an opportunity to experiment with methods and ideas for sharpening, refining or correcting currently held cognitive schemas. These bridging phases allowed faculty time for reflection and experimentation before making commitments to a new way of being or embracing a new stage of development. Our anecdotal evidence illustrated an unexpected progression in the stages and bridging phases of learning as faculty members reflected upon their teaching, sought information and/or activities to enhance their knowledge about teaching and learning, and employed their disciplinary research lens to investigate the teaching/learning processes in their own classrooms. Our findings were consistent with the results of Kreber and Cranton's (2000) research. The overlapping areas created space for faculty members to solidify their movement between the three stages and to assess new ideas that will be integrated into their cognitive and affective schemas.

In stage one (Learning about one's teaching), faculty members used their disciplinary lens to develop personal knowledge about their own teaching and learning style. Professors reported exhibiting curiosity about their students, interest in student learning, and acceptance of the professor's responsibility for creating a learning environment. Faculty members in this stage began to attend workshops on innovative teaching strategies and started evaluating their own classroom behaviors intentionally. Professors as adult learners began to document the effectiveness of changes in their teaching through student evaluations and occasional peer evaluations. The focus at this developmental stage appeared to be on the participant as a learner and being the recipient of some kind of praise and/ or acknowledgement for current work performed. Professors reported using their own experiences to help them make sense of their teaching strategies or practices and saw themselves confidently making good decisions that promoted student learning. If faculty learners experienced difficulties in this stage of growth, they could recognize that there was a problem and that they needed additional help dissecting the possible solutions, but they seldom sought out that help.

From our conversations across the six campuses, we identified when a faculty member began to move to a new stage. Typically, the transition was marked by a willingness to question teaching practices, sometimes retreating to the safety of what she or he knew worked or implementing new knowledge that allowed the professor to enter a new stage of teaching awareness and practice. The first bridging phase we called Engagement and Motivation, based on Schulman's (2002) Table of Learning because faculty participants reported moving from personal and professional experiences and improvised fixes to being motivated to pose questions about her or his teaching and reflect on a myriad of possible solutions to existing problems. As Schulman (2002) described in his Table of Learning, the Engagement and Motivation phase can lead to Knowledge and Understanding, which can be built upon to help individuals move to the Performance and Action level of learning. 


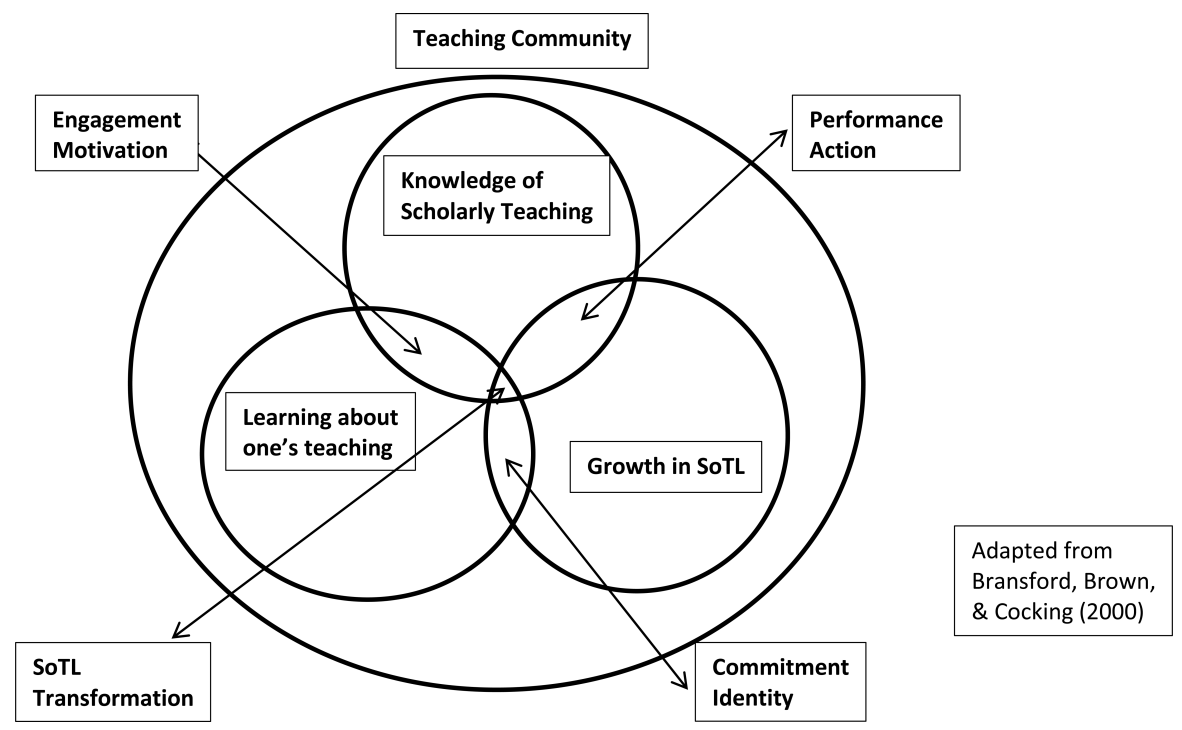

Figure 1. Faculty Processing Model for SoTL

Professors in the Engagement and Motivation bridging phase tended not to get bogged down by blaming themselves or the students, but moved to questioning standard teaching practices and beginning to incorporate new knowledge. At this point, faculty members often reported that they began to explore their classrooms as a potential venue for enhancing student learning outcomes. A professor in this bridging phase asked questions like: Do my strategies or tactics work as well as they might? or What should my role be in exploring the efficacy of my own teaching? The professor as learner moved from the awareness of her or his everyday teaching practice to developing a distinctive responsibility for teaching beyond his or her current expertise level. Yet sometimes, professors returned to stage one to re-establish their expertise. When these professors felt competent to cope with the ramifications or consequences of the answers to the questions they posed about student learning in their classrooms, then they were ready to engage in the next stage of learning.

In stage two of the model, Knowledge of Scholarly Teaching, faculty members developed and exchanged information about scholarly teaching and learning within and beyond their discipline and even outside of their institution (Randall, 2004). The University of Portland Carnegie group (2003) defined the scholarly teacher as one who "exhibits curiosity about her/his students and student learning," who "identifies issues and questions" related to aspects of student learning and who then develops, plans and implements strategies in a systematic fashion "designed to address or enhance student learning." Further, the scholarly teacher documented the outcomes consistent with his or her own disciplinary practices and reflected upon the ideas with others and built upon these findings systematically and iteratively (University of Portland, 2003). At this point in their development, professors identified issues and inquiries related to some fundamental aspect of student learning. Professors developed, planned, and implemented strategies consistent 
with best practices to address and enhance student learning based upon training and/or conversations with other colleagues or they retreated to build their own confidence and motivation before moving forward.

Of course, the Knowledge of Scholarly Teaching is a complex stage. Faculty participants documented or assessed the outcomes of their teaching strategies using tools aligned with the problems they experienced or relied on teaching methods consistent with their disciplinary focus. The faculty participant demonstrated growth in her or his systematic understanding of the complexities of teaching and learning because he or she reflected upon and shared ideas, designs, strategies, and outcomes. They mentored other teachers and provided leadership within the discipline or institution (University of Portland, 2003). Thus, the faculty member in the Knowledge of Scholarly Teaching stage displayed a commitment to teaching excellence and willingly applied new knowledge learned during faculty development sessions to her or his classes (Randall, Gayle, Wolfe, \& Kiser, 2004).

At this point, however, the faculty participant could not envision using one's classroom as a research site or connect assessment procedures with the implementation of a scholarly approach to teaching. For example, one professor reported comparing his usual testing method against his new group testing method to determine student learning and instituting several pedagogical theories for the alterations he made without attributing his actions to any understanding of SoTL. Plus, several professors in this stage appeared unable to articulate the commonalities they might share with other professors across disciplines in constructive ways to assess the efficacy of an overall learning strategy.

As faculty members began to move from stage two-Knowledge of Scholarly Teaching to stage three-Growth in the Scholarship of Teaching and Learning, they often reported engaging in the bridging phase we called Performance Action using definitions from Schulman's (2002) Table of Learning. In this bridging phase, professors became more goaloriented in articulating what they were trying to teach students and more connected to the assessment results they were obtaining. Faculty members reported being able to determine the success of one pedagogical choice over another and implementing specific courserelated research, although the professor would not identify the process as discipline-worthy research (Gayle, Randall, \& Langley, 2007). The faculty member's focus in this bridging phase was on student learning and examining the most motivating way to teach that acknowledges students as capable participants in the learning process. This bridging phase focused on the professor experimenting with a more systematic approach to assessing student learning and beginning the process of recognizing the connections between the systematic exploration of teaching and learning and the links to her or his disciplinary scholarship. To proceed to stage three-Growth in SoTL, the faculty member might well retreat to stage two-Knowledge about Scholarly Teaching, to solidify her or his knowledge of the possible applications and experiments for any given student learning outcome.

In the Growth in SoTL stage, a faculty member moved toward the practice of the SoTL. Professors began to develop enough pedagogical knowledge about teaching and learning to frame, or contextualize, their evolving knowledge and understanding of the teaching and learning process in terms of both significance and impact. In this stage, a collaborative process most often emerged between the professor and her or his students. The professor was able to draw upon the teaching and learning literature to inform her or his practice, to explore the field's vexing questions, and to enhance the institution's 
teaching and learning practices. The faculty member, as a practitioner of SoTL, valued scholarly investigations into teaching and learning using an approach consistent with the pedagogical framework of the specific discipline. During this stage, the professor willingly engaged in opportunities to make his or her scholarship public through presentations and publications.

Faculty members engaging in Scholarship of Teaching and Learning research often sought funding for that research, mentored others in doing this type of research, and demonstrated a comprehensive knowledge of teaching and learning research. Professors in this stage committed to advancing their own and others' knowledge about student learning, made their work accessible for peer review, and reviewed other SoTL projects to obtain desired results in student learning outcomes. At times, faculty members felt less confident in their abilities and revisited the Performance Action bridging phase during and beyond faculty development sessions.

In the third bridging phase, we called Commitment Identity, faculty members searched for theoretical and/or pedagogical models recognizing that there are multiple approaches to explore the efficacy of the teaching/learning process. As Shulman (2002) described in his Table of Learning, one's Commitment and Identity have been shaped through the actions taken and the critique of his or her efficacy in enhancing student learning. In this bridging phase, professors sought the full range of pedagogical ideas available and began to explore the intricacies of theory application to their own teaching practices. The Commitment Identity phase drew upon all resources in an effort to promote student learning. The professors acquired the internal authority to construct their students' learning in ways that allowed the faculty members to risk implementing innovative pedagogical approaches. They readily designed teaching strategies that they identified as being successful in enhancing student learning outcomes, or as needing modification. According to the faculty we consulted, it is at this point that faculty learning translated most readily to student learning.

Finally, at the heart of the Faculty Processing Model for SoTL was the Scholarship of Teaching and Learning transformation. If faculty learners advanced to this final overlapping state, the faculty member recognized the value of creating a teaching commons so that teaching became the public property of the community in which it resided. Student learning enhancement became a daily activity for engaged professors. They applied both their passion and their disciplinary approach to scholarship so that student learning enhancement was probable. It became routine for the professor to reflect upon and adjust to the needs of the students, the classroom, and the university.

In essence, the Faculty Processing Model for SoTL that emerged from the collection of anecdotal information acknowledged the fundamental faculty commitment to dialogue about teaching and student learning and was rooted in the professor's determination to put the knowledge gained through faculty development activities into practice, both creatively and concretely. As Cottrell and Jones' (2003) research suggested, the assumption in this model was that faculty will go beyond their disciplinary norms and expectations to make changes in their teaching by applying new knowledge and participating in advancing the results of their experiences across disciplines to enhance student learning. Our model took seriously the experimentation and development activities that are necessary to increase faculty members' capacity to document new ways of thinking and being. 


\section{TESTING THE MODEL}

To test our conceptualization, we developed a Likert-type survey that invited professors' responses to the various faculty development activities they were experiencing in order to determine if their involvement enriched their teaching and altered their students' learning (Gayle, Randall, \& Langley, 2010). We created a range of quantitative items such as "I had questions about my students' learning that I wanted to explore," "I have become more enthusiastic about teaching," "I changed my expectations for student learning," and "I have documented student learning." These items were designed to test the applicability of our Faculty Processing Model for SoTL's stages and bridging phases. Qualitative questions such as "What happened to make these sessions meaningful and helpful?", "To what extent did what you learned change how you approached your teaching?" and "Have you been able to employ any of what you learned in your classes?" allowed professors the opportunity to expand upon their responses and address their experiences in any way they felt appropriate.

Research on faculty learning during purposeful faculty development sessions was conducted by three of the six institutions in the original cluster ${ }^{2}$. A total of 169 professors answered the survey voluntarily. Qualitative results were analyzed for emerging themes that supported the phases and stages of the Faculty Processing Model for SoTL or that elicited positive or negative student learning outcomes. Almost half of these respondents had attended more than 15 hours of faculty development sessions. Sixty percent of the faculty surveyed had spent the majority of their time teaching undergraduates. The majority of respondents had been teaching 10 to 20 years.

\section{RESULTS}

Overall results revealed that faculty members engaged in professional development to: (a) interact, exchange, explore ideas about teaching and learning with colleagues; (b) increase repertoires of instructional theory and practice; and (c) experience and contribute to a sense of community. Faculty participants across institutions reported obtaining (a) strategies for engaging students in learning; (b) better approaches to assessment; and (c) increased reflection on classroom practice. When results are grouped under the constructs of the Faculty Processing Model for SoTL, the responses from the campuses were remarkably similar within the stages of the model.

Responses to Stage One-Learning about one's teaching-illustrated faculty commitment to learning about their own teaching as well as their commitment to the methods they felt worked for them. Seventy percent of the respondents agreed or strongly agreed with the statement that they were "Becoming more enthusiastic about their teaching" after participating in faculty development activities. Only $17 \%$ of these respondents reported that their "participation is expected" even though 47\% agreed or strongly agreed that "My institution's policy encourages faculty to reflect on their teaching practices." The faculty participants reported that they engaged in faculty development activities because they wanted to "engage with my peers" (66\%) and to "explore questions about teaching" (65\%).

The answers to the qualitative questions illustrated the tendency of faculty in this stage to concentrate on their own tried and true strategies and techniques ("Out of habit I forget new things and do the same old ones," "Although the sessions on teaching were well done and probably worthwhile, I don't think I took anything real specifically useful 
away from them."). Even though faculty at this stage of their development were interested in teaching better, they appeared to be committed to the way they had always functioned as a teacher: "All you get from these exchanges, are some new insights, and you inculcate them in your own methodologies, but basically there is no continuity to any of these discussions, no collective experimenting, no will on part of the college to get out of the traditional grooves and take bold actions." However, some respondents indicated their readiness to begin moving forward by reporting that: "I found this helpful because it made me realize that I wasn't alone-many other instructors don't know exactly how to deal with some students" and "It spoke to my developmental needs both as a teacher and a human being."

It was easy to identify those faculty members who began to think more about their teaching and began to pose the "what if I changed" questions. Faculty in this bridging stage-Engagement and Motivation - agreed or strongly agreed that they attended faculty development activities because they "had questions about student learning they wanted to explore" (66\%). However, fewer than half the faculty respondents reported that the faculty development activities "changed the kind of assessments they used in their teaching" (42\%). These faculty respondents suggested that the faculty development activities helped them feel "comfortable in trying new things even if they were not 'perfect' the first go around," and that they were confident in "trying new things and evaluating them from a variety of perspectives to keep my teaching dynamic." As one respondent claimed, "I greatly appreciate the opportunity to discuss almost any topic with my peers because teaching is so solitary and faculty development sessions allow me to talk to other instructors about common questions. It breaks down the isolation of teaching." Thus, faculty in this bridging stage reported changes in the way they "approached their work now" and "rethought their choice of teaching materials" as signs of preparation for entering a new phase of learning about the teaching and learning process.

Respondents addressing aspects of Stage Two-Knowledge about Scholarly Teachingmoved beyond tips and strategies to talk about implementing teaching practices that enhance student learning. The idea is that professors in this phase should discuss the complexities of pedagogical practices and put into practice many new ideas that would energize students and the professor. Sixty-one percent of the respondents agreed or strongly agreed that "I have changed the design of my courses" and 62\% indicated that they have improved their teaching. Overall, respondents in this phase of learning (65\%) reported that "My involvement heightened my interest in reading research on Teaching and Learning." When questioned about the impact of SoTL development opportunities, one professor responded that "Professional development has had a profound effect on my work. It reminded me that I need to broaden my focus rather than narrow it, which seems to be my personal tendency. The excitement of being a learner reminded me to take personally the experience of my students... There is a vast amount of knowledge about how to teach and learn and hence no excuses for boring presentations either by workshop facilitators or university professors!” The responses suggested that faculty members participating in faculty learning opportunities from this vantage point are likely to closely scrutinize their own teaching in terms of student learning outcomes and these insights seem to energize and invigorate their professional sensibilities.

Phase two-Performance Action-encouraged faculty growth at a deeper level that helped faculty begin to think about their teaching more systematically and to start experi- 
menting to enhance the likelihood that student learning outcomes would be achieved. Forty-one percent of the respondents reported that they "changed expectations for student learning," and that "the quality of student learning has changed." Only $23 \%$ of the respondents felt that "more students were achieving high standards of work" because of what the faculty member learned during faculty development activities. As one faculty member suggested in this bridging phase, professors need to "analyze the element of an idea or theory, synthesize and organize information and make judgments about information." In essence, faculty members in this bridging phase are student-centered enough to worry that "Students feel respected and included in the process of learning and so they can develop their own collaboration, tolerance, and respect/appreciation for each other's ideas." Professors in the Performance Action phase seemed to acknowledge the possibilities of learning and developed the willingness to think strategically about educational outcomes and implement specific techniques.

When faculty members engaged in the Growth in the Scholarship of Teaching and Learning stage, they framed what is known about teaching and understood ways to enhance student learning outcomes. They grasped various pedagogical theories and are willing to share their insights with colleagues. In our investigation, $32 \%$ of the respondents reported that after engaging in faculty development activities they have "documented improvements in student learners." Sixty-three percent of the respondents reported they had taken the first steps in this stage of their SoTL growth by reporting a "heightened interest in writing scholarship in my field or other fields." Only a handful of comments at each institution captured the faculty's understanding represented in this stage of the learning model. One professor illustrated an understanding of the focus on student learning claiming, "I have gained a greater sensitivity to the multiple ways in which students may or may not be able to interpret assignments, issues and topics and the adjustments necessary for deep understanding." Another faculty member reported that the best documentation of successful teaching was an undergraduate research methods course where two of his students were completing $\mathrm{PhDs}$ in his exact area of expertise. Still other faculty spoke to the informal conversations with colleagues as refining their approach to SoTL even if it wasn't a formal faculty development session.

In Bridging Phase Three of the Faculty Processing Model for SoTL_Commitment Identity - professors explored multiple ways to investigate the efficacy of the teaching/ learning process. The goal of this bridging phase was the creation of an internal authority that not only acknowledged teaching issues and explored their efficacy to enhance student learning, but made teaching community property. Only $31 \%$ of the respondents reported that "their work has had a positive influence on others." These faculty reported valuing "Interdisciplinary sharing and collaborating on insights and challenges, plus identifying skillful ways to teach and co-learn with students" and "Peer involvement that gave a variety of perspectives from other faculty and other institutions that were inspiring, re-invigorating and instrumental in the re-affirmation of my commitment to publically exploring my teaching." One faculty member best captured the overall response to this phase by summarizing these types of explorations:

The association of teaching and learning is so critical, but so is deep knowledge of student learning processes and values. Who are our students? Why are they in our classroom? What do they want? What do they need? How 
can we best meet their needs? Do they know how to be good learners? Can they be taught? How can we integrate teaching and learning? How can we make our classes truly interesting and meaningful? How can we assess whether deep learning is occurring? How can we support the whole student? How can we honor prior knowledge? How can we put theory into practice with energy and authenticity? These are the questions that I struggle with and these are the kinds of topics I long for in workshops and faculty development sessions.

Faculty respondents also reported interest, engagement, and experimentation with the Scholarship of Teaching and Learning. However, none of the answers reflected that faculty participants had in faculty development activities achieved a SoTL Transformation. Apparently, this state took longer to achieve or required projects to be completed that are peer reviewed and made public.

\section{DISCUSSION}

This study examined the utility of the Faculty Processing Model for SoTL to explore faculty development resulting in student learning. We sought to determine the outcomes of a variety of faculty development activities at campuses engaged in the Carnegie Campus Cluster program to enhance the participation in SoTL. Our investigation grew out of an inquiry by six institutions exploring the kinds of faculty learning necessary to move faculty from an interest in their own teaching success to a more comprehensive understanding of SoTL. Faculty development was seen as a vehicle for improving student learning and we proposed a model leading to this outcome. The model focused on faculty learning and assumed that faculty learning precedes student learning. Faculty learning was also assumed to possess different characteristics when compared to student learning. For example, the Faculty Processing Model for SoTL was grounded on the premise that adult learning is a transformational process that can be conceptualized as a series of fluid, nonlinear phases. Faculty members were viewed as disciplinary content experts who produced and critically assessed knowledge, and SoTL transformation occurred as faculty began to engage, perform, and commit to their scholarly teaching.

We used the Faculty Processing Model for SoTL to frame responses to a faculty development survey. Our results, both quantitative and qualitative, provided some support for the Faculty Processing Model for SoTL. It was clear that faculty members concentrating on enhancing their teaching simultaneously exhibited characteristics of several bridging phases and stages. Typically, over two-thirds of faculty participants reported reflecting upon their teaching practices. They were receptive to SoTL and considered whether current SoTL strategies might be implemented in any way in their classes.

Faculty participants in these development activities expressed a strong commitment to improve their teaching and to explore the nature of student learning. In general, they were drawn to sessions they perceived to be directly relevant to their work, to sessions that provided advanced strategies for engaging students in their own learning, and to sessions that gave faculty members a greater repertoire of classroom activities. They sought to apply their disciplinary insights in new ways that enhanced student learning. Many respondents also expressed a sense of relief in learning that colleagues shared similar concerns and challenges and that it was "comforting to know that even seasoned professors 
face these issues." Finally, there was some evidence of resistance to SoTL. Some faculty members were not able to move from the first phase of the model-Learning about one's own teaching. These faculty members reported not finding compelling reasons sufficient to motivate them to change their current approaches and behaviors for teaching students.

Although the majority of faculty participants reported that their development activities positively influenced the amount and the type of reflection they engaged in as well as their enthusiasm for teaching, they frequently did not perceive how the activities affected student learning in their classes. This suggested that faculty development activities focusing on student learning outcomes are less common than those focusing on new teaching strategies. Very little evidence supported claims that enhancing faculty learning significantly increased student learning.

This study was only one step in understanding the efficacy of faculty development activities in relation to their impact on student and faculty learning. Researchers need to follow the progress of faculty development activities designed to enhance faculty understanding of SoTL and affect student learning over time. This will require longitudinal research. Regardless of the time frame, learning about SoTL and its connection to student learning outcomes should guide faculty development activities. The bridging phases of engagement, performance and commitment provided opportunities for faculty to transform their curriculum and pedagogy. The goal of programmatic faculty development should be enhancing the likelihood that what is learned during the session will positively affect student learning outcomes. To achieve this end, it should be helpful to design faculty development efforts that view faculty members as learners.

We believe the challenges facing SoTL-driven faculty development efforts on each campus are substantial. For example, our faculty development activities might have been limited by our goals in the Carnegie Campus program. We may not have been intentional enough when designing activities that moved faculty participants from an interest in their own practice to growing in their application of SoTL due to time in the cluster and the amount of time that can be devoted to faculty development in any given year. When we began our work, our conceptualization of the model in more linear fashion was designed to help move a majority of our faculty to Knowledge of Scholarly Teaching (Randall, 2004). It is now apparent from this study that transitioning to Knowledge of Scholarly Teaching is more likely than to the Growth in SoTL stage. This vital step has been elusive, as the Faculty Processing Model for SoTL provided a silhouette of SoTL transformation that is not easily visualized and internalized. Nevertheless, faculty development that promotes reflection, awareness of common goals, and public dissemination of SoTL practices should be the basis of on-going professional growth.

Barbara Mae Gayle is Vice president for Academic Affairs and Dean of the Graduate School at Viterbo University as well as one of the co-editors for the Advances through Meta-analysis book series.

Nancy Randall was Vice-President, Canada, for ISSOTL and is an active reviewer for SoTL journals.

Lin Langley is teaching and working with students in the Communications Department of Douglas College in New Westminster, Canada.

Raymond W. Preiss is Professor of Communication Studies and Department Chair at Viterbo University as well as one of the co-editors for the Advances through Meta-analysis book series. 


\section{NOTES}

1. Two private and one state-sponsored university in the western United States, one private university in the Midwestern part of the United States, one College/University in Canada and one two-year institution in Canada collaborated in a Carnegie Campus Cluster.

2. One private US university and the two Canadian colleges participated.

\section{REFERENCES}

Bransford, J. D., Brown, A. L. \& Cocking, R. R. (2000). How People Learn. Washington, D.C.: National Academy Press.

Cottrell, S. A., \& Jones, E. A. (2003). Researching the scholarship of teaching and learning: An analysis of current curriculum practices. Innovative Higher Education, 27(3), 169-181.

Freezel, J., \& Welch, S. A. (2000). What is new and different about the Scholarship of Teaching. Journal of Association for Communication, 29, 250-256.

Gayle, B., Randall, N., \& Langley, L. (2007, October). Faculty development for the Scholarship of Teaching and Learning: Impact on student learning. Paper presented at the International Society for the Scholarship of Teaching and Learning conference, Sydney, Australia.

Gayle, B., Randall, N., \& Langley, L. (2010, October). Student learning enhanced through faculty learning: Translating faculty development into measurable student learning outcomes. Paper presented at the International Society for the Scholarship of Teaching and Learning conference, Liverpool, UK

Hoessler, C., Britnelll, J., \& Stockley, D. (2010). Assessing the impact of educational development through the lens of the Scholarship of Teaching and Learning. New Directions for Teaching and Learning, 122, 81-89.

Hubball, H. T., \& Burt, H. (2006). The Scholarship of Teaching and Learning: Theory, practice, integration in a faculty certificate program. Innovative Higher Education, 30(5), 327-344.24

Kreber, C., \& Cranton, P. A., (2000). Exploring the Scholarship of Teaching. Journal of Higher Education, 71(4). 476-495.

Lawler, P. A. (2003).Teachers as adult learners: A new perspective. New Directions for Adult and Continuing Education, 98, 15-22.

Ocha, A. (2011). The Scholarship of Teaching: Yesterday, today, and tomorrow. The Journal of the Professoriate, 6(1),100-116.

Randall, N. 2004. Navigating the Scholarship of Teaching and Learning. In B. Cambridge (Ed.), Campus Progress: Supporting the Scholarship of Teaching and Learning (pp.181-185). Washington, DC: AAHE.

Randall, N., Gayle, B., Wolffe, R., \& Kiser, L. (2004, October). Fanning the Scholarship of Teaching and Learning: Effective and innovative faculty development. Paper presented at the International Society for the Scholarship of Teaching and Learning conference, Bloomington, IN.

Shulman, Lee S. (2002, November/December). Making differences: A Table of Learning. Change, 34(6). 36-44.

University of Portland, (2003). Statement on scholarly teaching. Accessed 16 October 2010 at http://www.up.edu/tl/default.aspx?cid=5545\&pid=1196 
Wang, X., \& Hurley, S. (2012). Assessment as a scholarly activity: Faculty perceptions of and willingness to engage in student learning assessment. The Journal of General Education, 61(1), 1-15.

Weston, C. \& McAlpine, L. (2001). Making explicit the development towards the scholarship of teaching. In C. Kreber (Ed.), Scholarship Revisited: Perspectives on the scholarship of teaching (pp. 88-97). San Francisco: Jossey-Bass. 